\title{
Understanding Concerns, Sentiments, and Disparities Among Population Groups During the COVID-19 Pandemic Via Twitter Data Mining: Large-scale Cross-sectional Study
}

\author{
Chunyan Zhang ${ }^{1 *}$, MS; Songhua $\mathrm{Xu}^{1^{*}}, \mathrm{PhD}$; Zongfang $\mathrm{Li}^{1^{*}}, \mathrm{PhD}$; Shunxu $\mathrm{Hu}^{2}, \mathrm{BS}$ \\ ${ }^{1}$ Institute of Medical Artificial Intelligence, The Second Affiliate Hospital of Xi'an Jiaotong University, Xi'an, China \\ ${ }^{2}$ School of Mathematics and Statistics, Xi'an Jiaotong University, Xi'an, China \\ * these authors contributed equally
}

Corresponding Author:

Songhua Xu, PhD

Institute of Medical Artificial Intelligence

The Second Affiliate Hospital of Xi' an Jiaotong University

No.157 Xiwu Road

Xi'an

China

Phone: 8618710823698

Email: songhua xu1@163.com

\section{Abstract}

Background: Since the beginning of the COVID-19 pandemic in late 2019, its far-reaching impacts have been witnessed globally across all aspects of human life, such as health, economy, politics, and education. Such widely penetrating impacts cast significant and profound burdens on all population groups, incurring varied concerns and sentiments among them.

Objective: This study aims to identify the concerns, sentiments, and disparities of various population groups during the COVID-19 pandemic through a cross-sectional study conducted via large-scale Twitter data mining infoveillance.

Methods: This study consisted of three steps: first, tweets posted during the pandemic were collected and preprocessed on a large scale; second, the key population attributes, concerns, sentiments, and emotions were extracted via a collection of natural language processing procedures; third, multiple analyses were conducted to reveal concerns, sentiments, and disparities among population groups during the pandemic. Overall, this study implemented a quick, effective, and economical approach for analyzing population-level disparities during a public health event. The source code developed in this study was released for free public use at GitHub.

Results: A total of 1,015,655 original English tweets posted from August 7 to 12, 2020, were acquired and analyzed to obtain the following results. Organizations were significantly more concerned about COVID-19 (odds ratio [OR] 3.48, 95\% CI 3.39-3.58) and expressed more fear and depression emotions than individuals. Females were less concerned about COVID-19 (OR 0.73, 95\% CI 0.71-0.75) and expressed less fear and depression emotions than males. Among all age groups (ie, $\leq 18,19-29,30-39$, and $\geq 40$ years of age), the attention ORs of COVID-19 fear and depression increased significantly with age. It is worth noting that not all females paid less attention to COVID-19 than males. In the age group of 40 years or older, females were more concerned than males, especially regarding the economic and education topics. In addition, males 40 years or older and 18 years or younger were the least positive. Lastly, in all sentiment analyses, the sentiment polarities regarding political topics were always the lowest among the five topics of concern across all population groups.

Conclusions: Through large-scale Twitter data mining, this study revealed that meaningful differences regarding concerns and sentiments about COVID-19-related topics existed among population groups during the study period. Therefore, specialized and varied attention and support are needed for different population groups. In addition, the efficient analysis method implemented by our publicly released code can be utilized to dynamically track the evolution of each population group during the pandemic or any other major event for better informed public health research and interventions.

(J Med Internet Res 2021;23(3):e26482) doi: 10.2196/26482 


\section{KEYWORDS}

COVID-19; Twitter mining; infodemiology; infoveillance; pandemic; concerns; sentiments; population groups; disparities

\section{Introduction}

\section{Background}

Since December 2019, COVID-19 has rapidly spread all over the world and caused millions of deaths [1,2]. Although many countries have implemented various countermeasures $[3,4]$, an end to the pandemic is still not in sight. So far, COVID-19 has already exerted tremendous impacts across various aspects of human life, such as health, economy, politics, and education [5-8], whose influences may last for an unknown period. Such widely penetrating and long-lasting impacts are likely to cause disproportionate burdens on different population groups, incurring varied concerns and sentiments among them. Therefore, it is of great importance to understand the disparities in the responses of these population groups to COVID-19 for better informed public health research and intervention.

\section{Literature Reviews}

So far, two classes of methods have been utilized to study the impacts of COVID-19 on public and personal life, including large-scale social media mining approaches and cross-sectional analyses through online and offline questionnaires, which are briefly reviewed in the following text.

The first class of methods provides a fast and economical way to analyze the population impacts of COVID-19 through mining social media data generated during the pandemic. Currently, such methods have been employed in a number of studies. For example, Lwin et al [9] studied Twitter data to explore global trends of four emotions - fear, anger, sadness, and joy-as well as their relative salience. After studying the topics obtained by latent Dirichlet allocation topic modeling on Twitter text data, Abd-Alrazaq et al [10] identified the sentiments of four major topics and 12 subtopics, and showed that all topics were positive except for two (ie, death and racial discrimination). Similarly, Hung et al [11] adopted the Valence Aware Dictionary and Emotional Reasoner (VADER) model to analyze the sentiments expressed in user tweets and found that positive, neutral, and negative emotions accounted for $48.2 \%, 20.7 \%$, and $31.1 \%$ of the tweets, respectively.

Despite the informative understanding regarding people's sentiments provided by these prior studies, it is noted that these existing methods tend to treat their study population as a whole in the analysis, ignoring likely disparities among population groups. Case reports from many countries and epidemiological research on COVID-19 state that the morbidity and mortality of COVID-19 are related to age and gender [12-14], calling for a more fine-grained analysis regarding the concerns and sentiments of each population group during the pandemic.

The second class of methods has been popularly leveraged to understand the health statuses of population groups, uncover health-related factors, and carry out disease epidemiology research. Table 1 [15-20] lists some representative cross-sectional surveys on COVID-19. Compared with the first class of data mining methods, cross-sectional studies can provide richer and more fine-grained information through well-controlled questionnaires, which is of great use for analyzing the detailed disparities of population groups.

Table 1. Representative cross-sectional studies on COVID-19.

\begin{tabular}{|c|c|c|c|c|}
\hline $\begin{array}{l}\text { Author and refer- } \\
\text { ence }\end{array}$ & Study target area & $\begin{array}{l}\text { Study period (all in } \\
2020 \text { ) }\end{array}$ & $\begin{array}{l}\text { No. of participants (on- } \\
\text { line or offline) }\end{array}$ & Highlights \\
\hline Liu et al [15] & $\begin{array}{l}\text { Wuhan and sur- } \\
\text { rounding cities, } \\
\text { China }\end{array}$ & $\begin{array}{l}\text { January 30-February } \\
8\end{array}$ & 300 (online) & $\begin{array}{l}\text { Gender differences exist in posttraumatic stress symptoms } \\
\text { during COVID-19: females suffer more than males. }\end{array}$ \\
\hline Lu et al [16] & Fujian, China & April 6-22 & 2299 (offline) & $\begin{array}{l}\text { Work differences exist in fear, anxiety, and depression } \\
\text { emotions in hospitals during COVID-19: medical workers } \\
\text { suffer more than administrative workers. }\end{array}$ \\
\hline Nelson et al [17] & $\begin{array}{l}\text { Parts of the United } \\
\text { States }\end{array}$ & March 14-16 & 9009 (online) & $\begin{array}{l}\text { Age differences exist in concerns about COVID-19: people } \\
\text { aged } 40-54 \text { years and } 55-75 \text { years are very worried and } \\
\text { extremely worried population groups, respectively. }\end{array}$ \\
\hline Groarke et al [18] & $\begin{array}{l}\text { The United King- } \\
\text { dom }\end{array}$ & March 23-April 24 & 1964 (online) & $\begin{array}{l}\text { Age differences exist in loneliness during COVID-19: } \\
\text { young people suffer most. }\end{array}$ \\
\hline Azlan et al [19] & Malaysia & March 27-April 3 & 4850 (online) & $\begin{array}{l}\text { Gender, age, region, occupation, and income differences } \\
\text { exist in public knowledge toward COVID- } 19 \text {. }\end{array}$ \\
\hline $\begin{array}{l}\text { Ahmad and Murad } \\
\text { [20] }\end{array}$ & Iraqi Kurdistan & Not stated & 516 (online) & $\begin{array}{l}\text { Age differences exist in mental health during COVID-19: } \\
\text { young people aged 18-35 years are facing psychological } \\
\text { anxiety. }\end{array}$ \\
\hline
\end{tabular}

However, the shortcomings of both online and offline cross-sectional studies are also commonly acknowledged. In particular, launching offline questionnaires during the COVID-19 pandemic may pose eminent public health hazards because of the risk of virus transmission through personal contacts. Online questionnaires also have their own challenges, mainly difficulties in finding an adequate number of willing participants to complete the online questionnaires honestly and 
at a high quality. The operational obstacle of online questionnaires is further elevated if repeated surveys are intended to track the dynamic evolution of population groups regarding their thoughts and needs [21].

Recognizing the limitations of the two classes of existing study methods, in this work, we conducted a new cross-sectional study via large-scale Twitter data mining. Through this method, we aimed to identify the concerns, sentiments, and disparities of various population groups during the COVID-19 pandemic in fine granularity without administrating any online or offline questionnaires. The advantage of our approach lies in its economic and efficient way of gathering multifaceted awareness information from population groups and their disparities. With such an understanding of the concerns and sentiments of population groups regarding COVID-19, specialized attention and customized programs can be developed to assist each population group. It is noted that the method implemented through our social media data mining approach can be easily repurposed to study the evolution of different population groups during any major public health event for better informed public health research and interventions. The source code developed in this study has been released for free public use at GitHub [22].

\section{Methods}

As shown in Figure 1, the cross-sectional method proposed in this study consists of three steps. The implementation details of each step are described in the following sections.

Figure 1. The structure of our cross-sectional method. API: application programming interface; POMS: Profile of Mood States.

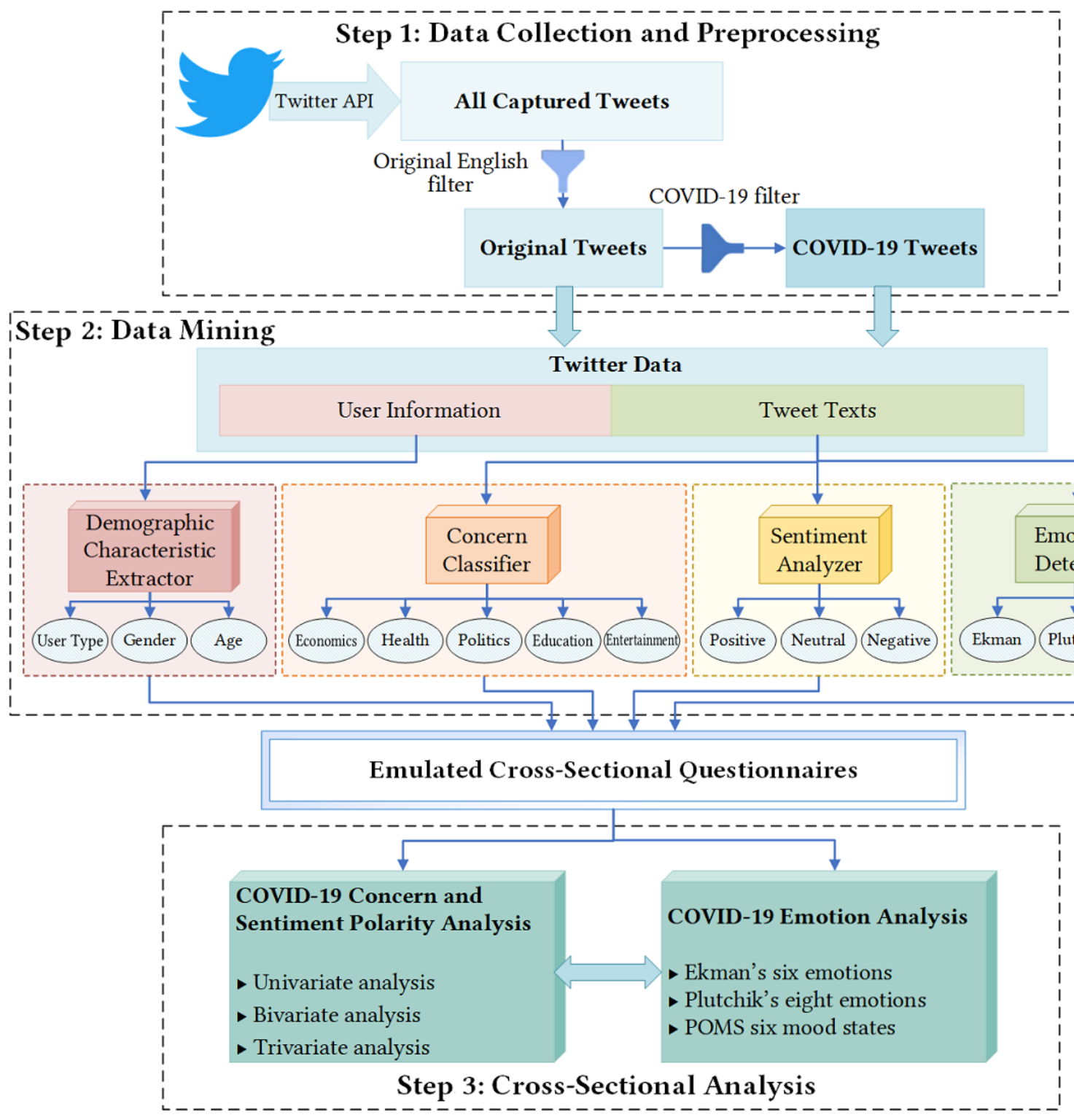

\section{Data Collection and Preprocessing}

The Twitter data used in this study were collected by sampled stream application programming interface v1 [23] and v2 [24] from Twitter Developer Labs, which can stream about $1 \%$ of publicly available tweets in real time. Meanwhile, detailed author data from all the tweets were collected to extract population characteristics. Unlike those in other research studies on Twitter [9-11], the data captured in this study are a random sampling of all Twitter data without using any filter, which can 
better reflect the common opinions in people's daily lives. As of November 2020, we have collected, in total, more than 600 million tweets (ie, over 2 Terabytes) during the COVID-19 pandemic.

In the data preprocessing step, an original English filter and a COVID-19 filter were used to generate the original and COVID-19 tweet data sets based on all the captured tweets.
Since original tweets can better reflect the authors' dynamic thoughts and sentiments, and English tweets comprise over half of all tweets (see Figure 2), we only focused on original English tweets, which can be filtered by the attributes of the tweet object. In order to obtain COVID-19 tweets, we made a filter pattern that is composed of 590 COVID-19 keywords and hashtags provided by Twitter COVID-19 filter rules [25].

Figure 2. The language distribution of tweets. ar: Arabic; en: English; es: Spanish; hi: Hindi; others: other languages; pt: Portuguese.

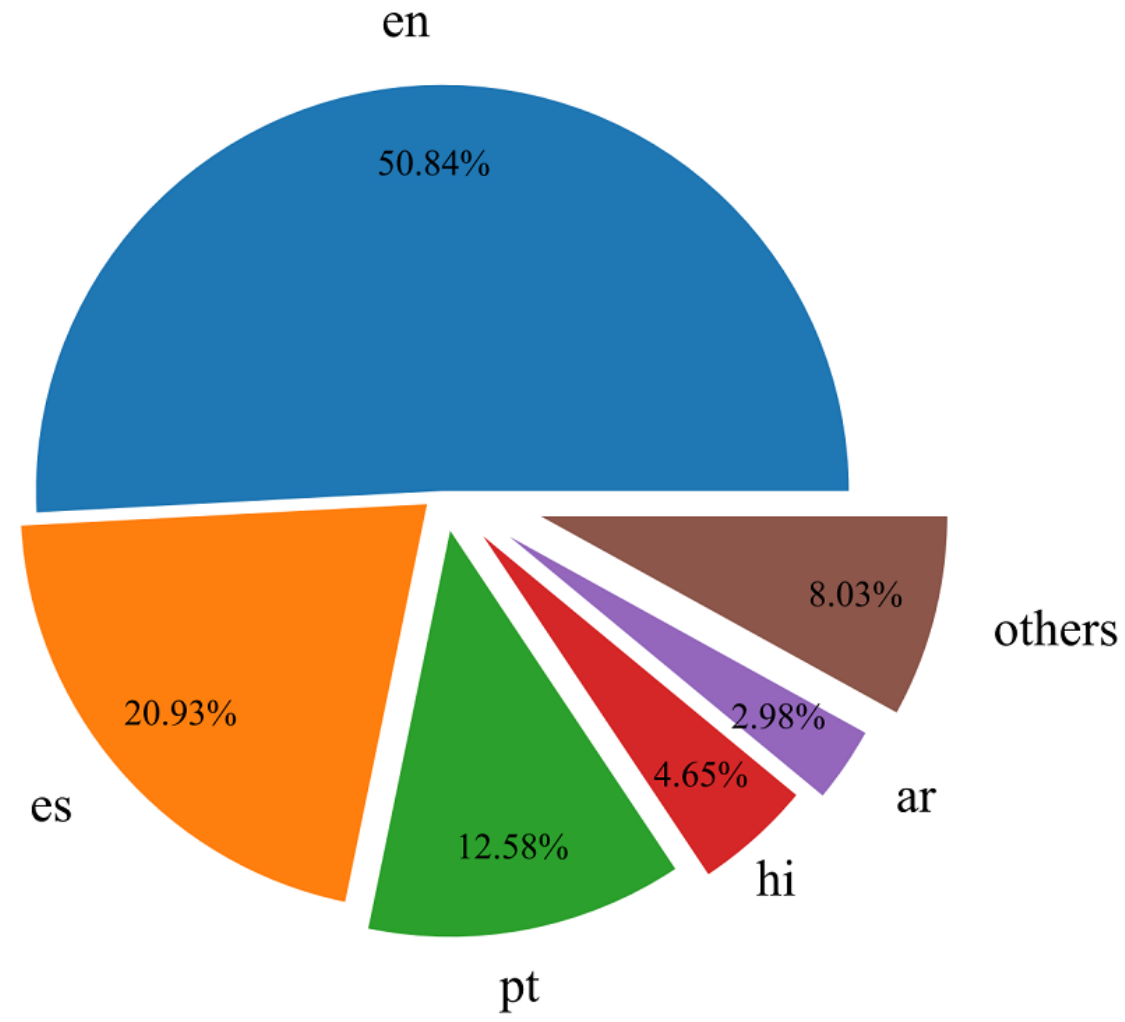

\section{Data Mining}

Data mining is the key step in emulating cross-sectional questionnaires based on the two tweet data sets. This step contained four intelligent modules: demographic characteristic extractor, concern classifier, sentiment analyzer, and emotion detector.

\section{Demographic Characteristic Extractor}

This module was used to extract three demographic characteristics-user type, gender, and age-through profile images, screen names, names, and biographies. It was implemented by an open source package of the M3 (multimodal, multilingual, and multi-attribute) model [26], which is a multimodal deep neural system trained on a massive data set, composed of Twitter, IMDB, and Wikipedia data [27], for demographic inference. In this M3 model, user type (ie, person or organization) and gender (ie, male or female) were modeled as binary classification tasks, while age was modeled as a 4-class classification task with the following age groups: $\leq 18,19-29$, $30-39$, and $\geq 40$ years of age. As shown in Figure 3, the structure of the M3 model consisted of two separate pipelines-image pipeline and text pipeline-and a shared pipeline. The image pipeline was employed to process profile images using the dense convolutional network (DenseNet) [28], and the text pipeline was used for processing three text sources of screen names, names, and biographies by adopting three character-based neural networks. The shared pipeline combined the outputs of the two separate pipelines and then mainly applied two fully connected dense layers to predict the user type, gender, and age state of each Twitter user. All of these pipelines were fine-tuned to capture accurate demographic features. For more detailed information, readers can refer to the original literature [26]. 
Figure 3. The structure of the M3 (multimodal, multilingual, and multi-attribute) model for inferring user type, gender, and age from profile information. DenseNet: dense convolutional network; ReLU: rectified linear unit.

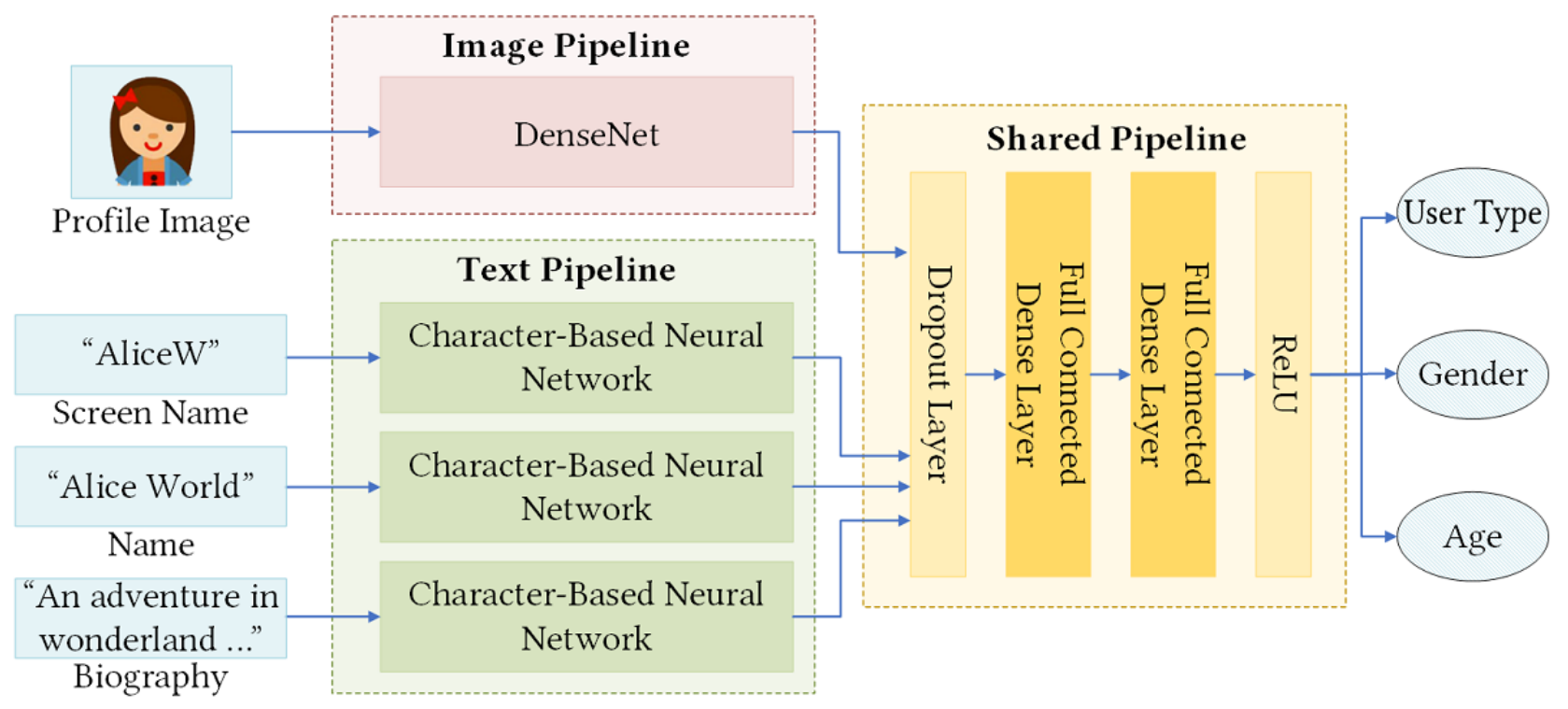

We tested the M3 model on a subset of our original English tweets that carried ground-truth labels of user type, gender, and age explicitly or implicitly; the detection procedure is explained in detail in Multimedia Appendix 1. The benchmark performance of the M3 model on this subset is as follows: for user type, gender, and age, the accuracy scores are $99.07 \%$, $95.88 \%$, and $77.65 \%$, respectively, and the macro-F1 scores are $0.9860,0.9572$, and 0.7311 , respectively.

\section{Concern Classifier}

This module was used to classify the tweets into five categories of human life-economics, politics, health, education, and entertainment-which was based on our self-designed matching patterns. First, five specialized vocabulary dictionaries were collected and constructed from Oxford Reference and other sources, including an economic vocabulary (ie, A Dictionary of Economics [29] and The Economist [30]) and a political vocabulary (ie, A Concise Oxford Dictionary of Politics and International Relations [31]). Then, the vocabulary dictionaries were imported into the matching patterns in a regular expression format, with which we labeled all the tweets.

\section{Sentiment Analyzer}

This module calculated the sentiment polarities of the tweets based on the VADER [32] model. The VADER model is a sentiment analysis tool based on lexicons of sentiment-related words, which can automatically classify each word in the lexicon as positive, neutral, or negative. The range of the sentiment polarity is -1 to 1 , which is divided into three subranges: negative ( -1 to -0.05$)$, neutral $(-0.05$ to 0.05$)$, and positive (0.05 to 1$)$.

\section{Emotion Detector}

This module is based on an emotion recognition model on Twitter [33], which utilizes a character-based trained recurrent neural network algorithm. It employs three emotion models to recognize different human emotions, including Ekman's six basic emotions model [34]; Plutchik's eight primary emotions model, also known as the emotion wheel [35]; and the Profile of Mood States (POMS) model [36], which measures six mood states. Based on the above-mentioned modules, the template of the emulated cross-sectional questionnaire is shown in Table 2. 
Table 2. The template of the cross-sectional questionnaire.

\begin{tabular}{|c|c|}
\hline Question category & Response categories \\
\hline \multicolumn{2}{|l|}{ Population characteristic } \\
\hline \multirow[t]{2}{*}{ User type } & Person \\
\hline & Organization \\
\hline \multirow[t]{2}{*}{ Gender } & Male \\
\hline & Female \\
\hline \multirow[t]{4}{*}{ Age (years) } & $\leq 18$ \\
\hline & $19-29$ \\
\hline & $30-39$ \\
\hline & $\geq 40$ \\
\hline \multicolumn{2}{|l|}{ Concern } \\
\hline \multirow[t]{2}{*}{ Economics } & Concerned \\
\hline & Unconcerned \\
\hline \multirow[t]{2}{*}{ Health } & Concerned \\
\hline & Unconcerned \\
\hline \multirow[t]{2}{*}{ Politics } & Concerned \\
\hline & Unconcerned \\
\hline \multirow[t]{2}{*}{ Education } & Concerned \\
\hline & Unconcerned \\
\hline \multirow[t]{2}{*}{ Entertainment } & Concerned \\
\hline & Unconcerned \\
\hline \multicolumn{2}{|l|}{ Sentiment polarity } \\
\hline Negative & -1 to -0.05 \\
\hline Neutral & -0.05 to 0.05 \\
\hline Positive & 0.05 to 1 \\
\hline \multicolumn{2}{|l|}{ Emotions } \\
\hline Ekman's six emotions: anger, disgust, fear, joy, sadness, and surprise & 0 to 1 for each emotion \\
\hline $\begin{array}{l}\text { Plutchik's eight emotions: anger, disgust, fear, joy, sadness, surprise, trust, } \\
\text { and anticipation }\end{array}$ & 0 to 1 for each emotion \\
\hline $\begin{array}{l}\text { POMS }{ }^{\mathrm{a}} \text { six emotions: anger, depression, fatigue, vigor, tension, and con- } \\
\text { fusion }\end{array}$ & 0 to 1 for each emotion \\
\hline
\end{tabular}

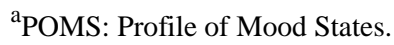

\section{Cross-sectional Analysis}

The purpose of this step was to analyze the concerns and sentiments of different population groups in response to COVID-19 based on the Twitter data mining outcomes of the emulated questionnaire. It includes two parts: the COVID-19 concern and sentiment polarity analysis and the COVID-19 emotion analysis. The odds ratio (OR) was employed in these two parts to compare the relative ratios of population groups under multiple variable conditions. Meanwhile, we used the chi-square test to measure the significance level of difference (ie, $P$ value) under each condition.

\section{Results}

\section{Overall Analysis}

During the COVID-19 pandemic, various emotions were expressed by the general public. To study the disparities between different population groups during this period, we conducted a cross-sectional analysis on the daily Twitter data collected from August 7 to 12, 2020. In total, 7,590,844 unfiltered tweets were captured during the research period, of which 1,015,655 were original English tweets; these are referred to as the original data set. From this original data set, 27,216 tweets were related to COVID-19; these are referred to as COVID-19 data set. The statistical distributions and $P$ values, by chi-square test, of the two data sets are shown in Table 3.

We can see from Table 3 that the population groups under each variable all showed significant differences $(P<.001)$ in response 
to COVID-19. As shown in Table $3,89.94 \%$ of the total participants were persons and $10.06 \%$ were organizations. As a comparison, $73.00 \%$ and $27.00 \%$ of COVID-19-related participants were persons and organizations, respectively. The total proportion of male participants on social media was slightly higher than that of females (52.74\% vs $47.26 \%)$, while this gap was further widened to $60.38 \%$ versus $39.62 \%$ under COVID-19, respectively. The total proportions of the four age groups $-\leq 18,19-29,30-39$, and $\geq 40$ years of age-were $37.93 \%, 38.42 \%, 11.41 \%$, and $12.24 \%$, respectively; from this, it can be inferred that people below 30 years of age are more active on social media. Under COVID-19, the proportions increased in the age groups above 30 years and decreased in the age groups below 30 years; thus, the proportions of the four age groups changed to $17.83 \%, 29.18 \%, 18.32 \%$, and $34.67 \%$, respectively. The total proportions of the five topics-economics, health, politics, education, and entertainment-were $13.99 \%, 13.90 \%, 7.27 \%, 6.38 \%$, and $7.79 \%$, respectively; under COVID-19, their proportions changed to $34.30 \%, 22.60 \%, 19.97 \%, 15.74 \%$, and $6.38 \%$, respectively. The total proportions of positive, neutral, and negative sentiments were $42.46 \%, 31.38 \%$, and $26.16 \%$, respectively; the mean sentiment polarity was 0.1067 (SD 0.4647). Under COVID-19, the proportions of positive, neutral, and negative sentiments were $43.15 \%, 24.37 \%$, and $32.48 \%$, respectively; the mean sentiment polarity fell to 0.0659 (SD 0.4941).

Table 3. Statistical distributions of the emulated questionnaire answers.

\begin{tabular}{|c|c|c|c|}
\hline Variable & Total tweets, $\mathrm{n}(\%)^{\mathrm{a}}$ & COVID-19-related tweets, n (\%) & $P$ value \\
\hline Overall & $1,015,655(100)$ & $27,216(100)$ & $\mathrm{N} / \mathrm{A}^{\mathrm{b}}$ \\
\hline \multicolumn{4}{|l|}{ User type } \\
\hline Person & $913,480(89.94)$ & $19,869(73.00)$ & $<.001$ \\
\hline Organization & $102,175(10.06)$ & $7347(27.00)$ & N/A \\
\hline \multicolumn{4}{|l|}{ Gender } \\
\hline Male & $481,770(52.74)$ & $11,997(60.38)$ & $<.001$ \\
\hline Female & $431,710(47.26)$ & $7872(39.62)$ & N/A \\
\hline \multicolumn{4}{|l|}{ Age (years) } \\
\hline$\leq 18$ & $346,483(37.93)$ & $3542(17.83)$ & $<.001$ \\
\hline $19-29$ & $350,959(38.42)$ & $5798(29.18)$ & N/A \\
\hline $30-39$ & $104,228(11.41)$ & $3640(18.32)$ & N/A \\
\hline$\geq 40$ & $111,810(12.24)$ & $6889(34.67)$ & N/A \\
\hline \multicolumn{4}{|l|}{ Concern } \\
\hline Economics & $142,090(13.99)$ & $9334(34.30)$ & $<.001$ \\
\hline Health & $141,176(13.90)$ & $6152(22.60)$ & N/A \\
\hline Politics & $73,838(7.27)$ & $5434(19.97)$ & N/A \\
\hline Education & $64,799(6.38)$ & $4284(15.74)$ & N/A \\
\hline Entertainment & $79,119(7.79)$ & $1736(6.38)$ & N/A \\
\hline \multicolumn{4}{|l|}{ Sentiment polarity } \\
\hline Overall ( -1 to 1$)$, mean (SD) & $0.1067(0.4647)$ & $0.0659(0.4941)$ & $<.001$ \\
\hline Positive ( -1 to 0.05 ) & $431,247(42.46)$ & $11,744(43.15)$ & $<.001$ \\
\hline Neutral $(-0.05$ to 0.05$)$ & $318,713(31.38)$ & $6632(24.37)$ & N/A \\
\hline Negative ( 0.05 to 1$)$ & $265,695(26.16)$ & $8840(32.48)$ & N/A \\
\hline
\end{tabular}

${ }^{a}$ All values are expressed as $n(\%)$, except for overall sentiment polarity, which is expressed as mean (SD).

${ }^{\mathrm{b}} P$ values were calculated for the main variables and not for individual responses.

The above analysis cannot provide fine-grained differences between population groups under multivariate conditions. To understand these differences more clearly, we adopted a cross-sectional analysis based on the emulated questionnaire outcomes, which consists of two parts: one is COVID-19 concern and sentiment polarity analysis, including univariate, bivariate, and trivariate analysis, and the other one is COVID-19 emotion analysis, including three emotion models. The analysis process and results are presented in the following sections. 
COVID-19 Concern and Sentiment Polarity Analysis

\section{Univariate Analysis}

The population characteristics in this study included four variables-user type, gender, age, and concern — on which we first performed a univariate statistical analysis of COVID-19 concerns and sentiment polarities. The results are shown in Figure 4.

Figure 4. Univariate analysis of COVID-19 concerns and sentiment polarities among different population groups. OR: odds ratio.

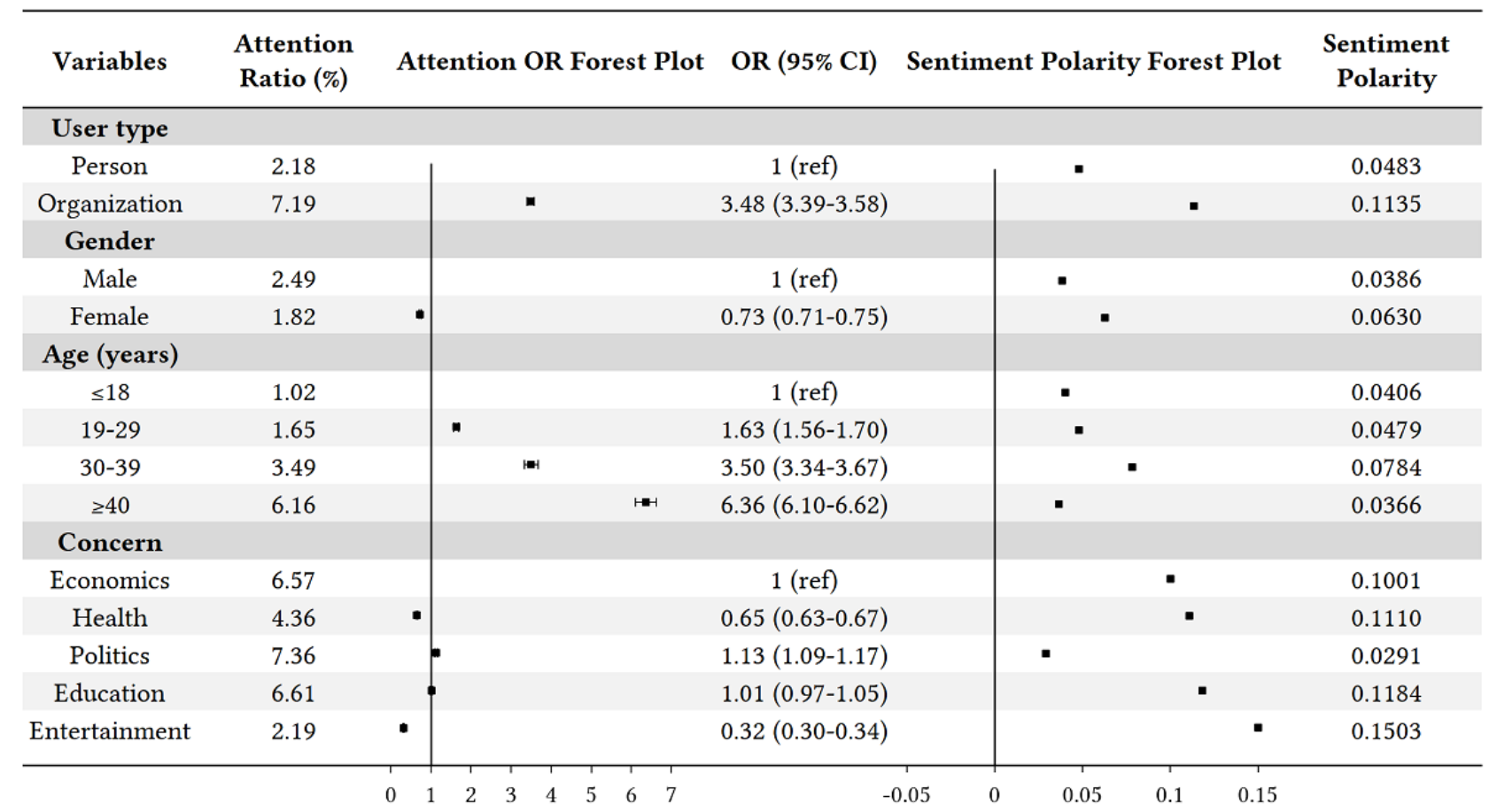

It can be seen that the organizations' attention ratio $(7.19 \%)$ to COVID-19 was significantly higher than that of individuals $(2.18 \%)$, and the attention OR of organizations was $3.48(95 \%$ CI 3.39-3.58) compared with individuals. Moreover, organizations' sentiment polarity (0.1135) was more positive than that of individuals (0.0483). The COVID-19 attention ratio of females $(1.82 \%)$ was a bit lower than that of males $(2.49 \%)$, with an attention OR of 0.73 (95\% CI 0.71-0.75). Meanwhile, females were more positive than males, and the sentiment polarities were 0.0630 and 0.0386 for females and males, respectively. In addition, COVID-19 attention increased significantly with age. Among the four age groups, the attention ORs of the groups that were 19 to 29 years, 30 to 39 years, and 40 years or older were 1.63 (95\% CI 1.56-1.70), 3.50 (95\% CI 3.34-3.67) and 6.36 (95\% CI 6.10-6.62), respectively, in comparison with the group that was 18 years or less, which implies that older people are more concerned about COVID-19. The group that was 40 years or older was less positive than other age groups, with a sentiment polarity of 0.0366 . For the concern variable, the COVID-19 attention ratios for politics (7.36\%), education $(6.61 \%)$, and economics $(6.57 \%)$ were relatively high, followed by health $(4.36 \%)$ and entertainment $(2.19 \%)$. The sentiment polarity of political topics $(0.0291)$ was the lowest among these topics, followed by economic (0.1001), health (0.1110), education (0.1184), and entertainment (0.1503) topics.

In general, these data indicate that organizations, as compared to individuals; males, as compared to females; and older people, as compared to young people, are more concerned about the pandemic. In addition, these data indicate that people are more concerned about politics, education, and economics under COVID-19.

\section{Bivariate Analysis}

Furthermore, we performed a bivariate analysis on COVID-19 attention and sentiment polarity by crossing any two population characteristic variables, as shown in Figure 5. 
Figure 5. Bivariate analysis of COVID-19 concerns and sentiment polarities among different population groups. OR: odds ratio; Org: organization.

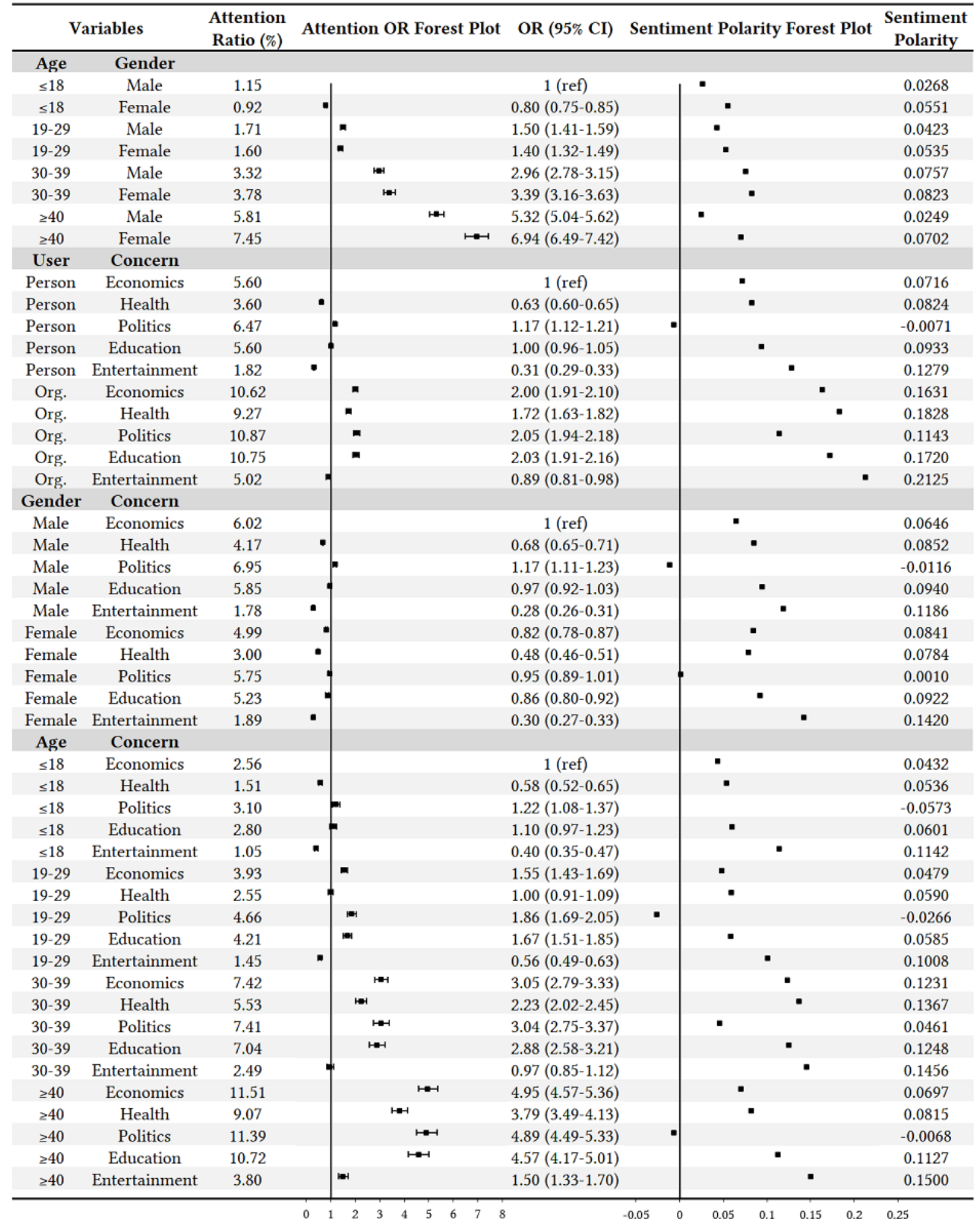

It can be seen that many results are consistent with the univariate analysis in the previous section. For example, under the combination of age and gender variables, the attention ratios grew with age, both for males and females. Moreover, females were more positive than males in all age groups. Under the combination of user type and concern variables, the order of concerns for individuals is politics, education, economics, health, and entertainment, which is similar to the univariate results.
However, there are still some noteworthy differences. First, not all females of different ages paid less attention to COVID-19 than males, but as individuals got older, females became more concerned than males, with the highest attention ratio of $7.45 \%$ and OR of 6.94 (95\% CI 6.49-7.42) in females 40 years or older. Second, males 40 years or older (0.0249) and 18 years or younger $(0.0268)$ were the least positive among all population groups. Third, different from the univariate concern analysis, the order of concerns for groups 30 to 39 years and 40 years or 
older changed to economics, politics, education, health, and entertainment.

From the bivariate results, we can see that not all the population groups obeyed the same rules, but some of them presented worthy differences under multivariable conditions. We further conducted a deeper exploration in the following trivariate analysis.

\section{Trivariate Analysis}

In this part of the study, we crossed the three variables-gender, age, and concern - of population characteristics to study the COVID-19 responses, and a total of 40 combinations were produced, as shown in Figure 6. Since gender and age attributes did not exist in the organization group, this trivariate analysis only concentrated on individuals.

Figure 6. Trivariate analysis of COVID-19 concerns and sentiment polarities among different population groups. OR: odds ratio.

\begin{tabular}{|c|c|c|c|c|c|c|c|c|c|}
\hline \multirow[b]{2}{*}{ Gender } & \multicolumn{2}{|c|}{ Variables } & \multirow[t]{2}{*}{$\begin{array}{c}\text { Attention } \\
\text { Ratio (\%) }\end{array}$} & \multicolumn{2}{|r|}{ Attention OR Forest Plot } & \multirow[t]{2}{*}{ OR $(95 \% \mathrm{CI})$} & \multirow[t]{2}{*}{ Sentiment } & \multirow[t]{2}{*}{ Polarity Forest Plot } & \multirow[t]{2}{*}{$\begin{array}{c}\text { Sentiment } \\
\text { Polarity }\end{array}$} \\
\hline & Age & Concern & & & & & & & \\
\hline Male & $\leq 18$ & Economics & 2.65 & 1 & 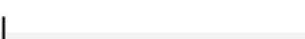 & 1 (ref) & & - & 0.0361 \\
\hline Male & $\leq 18$ & Health & 1.75 & $\mathbf{m}$ & & $0.66(0.57-0.76)$ & & - & 0.0629 \\
\hline Male & $\leq 18$ & Politics & 3.38 & & $=-1$ & $1.29(1.10-1.50)$ & - & & -0.0658 \\
\hline Male & $\leq 18$ & Education & 3.17 & & $=-1$ & $1.20(1.03-1.41)$ & & - & 0.0444 \\
\hline Male & $\leq 18$ & Entertainment & 1.06 & - & & $0.39(0.32-0.48)$ & & - & 0.0991 \\
\hline Male & $19-29$ & Economics & 4.12 & & 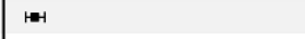 & $1.58(1.41-1.77)$ & & - & 0.0292 \\
\hline Male & $19-29$ & Health & 2.73 & & 4 & $1.03(0.91-1.17)$ & & - & 0.0613 \\
\hline Male & $19-29$ & Politics & 4.83 & & $\mapsto-1$ & $1.87(1.64-2.13)$ & - & & -0.0757 \\
\hline Male & $19-29$ & Education & 4.13 & & $H$ & $1.58(1.38-1.82)$ & & - & 0.0402 \\
\hline Male & $19-29$ & Entertainment & 1.36 & $m$ & & $0.51(0.43-0.60)$ & & - & 0.0434 \\
\hline Male & $30-39$ & Economics & 6.96 & & $\mapsto-1$ & $2.75(2.45-3.09)$ & & - & 0.1194 \\
\hline Male & $30-39$ & Health & 5.40 & & $H=-1$ & $2.10(1.84-2.39)$ & & - & 0.1381 \\
\hline Male & $30-39$ & Politics & 6.61 & & $\mapsto-1$ & $2.60(2.28-2.97)$ & & - & 0.0777 \\
\hline Male & $30-39$ & Education & 6.25 & & $\mapsto-1$ & $2.45(2.12-2.83)$ & & - & 0.1368 \\
\hline Male & $30-39$ & Entertainment & 1.84 & $=1$ & & $0.69(0.57-0.83)$ & & & 0.2053 \\
\hline Male & $\geq 40$ & Economics & 10.97 & & $\mapsto-1$ & $4.53(4.08-5.03)$ & & - & 0.0653 \\
\hline Male & $\geq 40$ & Health & 8.54 & & $\mapsto-1$ & $3.43(3.08-3.83)$ & & - & 0.0815 \\
\hline Male & $\geq 40$ & Politics & 11.62 & & $\longmapsto$ & $4.83(4.33-5.39)$ & - & & -0.0082 \\
\hline Male & $\geq 40$ & Education & 10.18 & & $\longmapsto$ & $4.16(3.71-4.68)$ & & - & 0.1175 \\
\hline Male & $\geq 40$ & Entertainment & 3.54 & & $1 \oplus$ & $1.35(1.16-1.56)$ & & - & 0.1368 \\
\hline Female & $\leq 18$ & Economics & 2.46 & t & 1 & $0.93(0.81-1.07)$ & & - & 0.0518 \\
\hline Female & $\leq 18$ & Health & 1.32 & $m$ & & $0.49(0.43-0.57)$ & & - & 0.0443 \\
\hline Female & $\leq 18$ & Politics & 2.78 & & H & $1.05(0.89-1.25)$ & - & & -0.0456 \\
\hline Female & $\leq 18$ & Education & 2.38 & 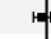 & 4 & $0.90(0.75-1.07)$ & & - & 0.0840 \\
\hline Female & $\leq 18$ & Entertainment & 1.04 & 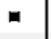 & & $0.39(0.31-0.47)$ & & - & 0.1315 \\
\hline Female & $19-29$ & Economics & 3.71 & & 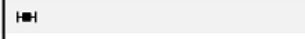 & $1.42(1.26-1.59)$ & & - & 0.0712 \\
\hline Female & $19-29$ & Health & 2.40 & - & & $0.90(0.80-1.02)$ & & - & 0.0567 \\
\hline Female & $19-29$ & Politics & 4.47 & & $\mapsto-1$ & $1.72(1.50-1.97)$ & & - & 0.0301 \\
\hline Female & $19-29$ & Education & 4.31 & & $E-1$ & $1.65(1.44-1.90)$ & & - & 0.0785 \\
\hline Female & $19-29$ & Entertainment & 1.56 & $m$ & & $0.58(0.49-0.70)$ & & - & 0.1675 \\
\hline Female & $30-39$ & Economics & 8.28 & & $\mapsto-1$ & $3.32(2.92-3.78)$ & & - & 0.1289 \\
\hline Female & $30-39$ & Health & 5.70 & & $1=-1$ & $2.22(1.94-2.55)$ & & - & 0.1351 \\
\hline Female & $30-39$ & Politics & 9.12 & & $\longmapsto$ & $3.69(3.17-4.29)$ & & & -0.0031 \\
\hline Female & $30-39$ & Education & 8.52 & & $\longmapsto$ & $3.42(2.91-4.02)$ & & - & 0.1084 \\
\hline Female & $30-39$ & Entertainment & 4.27 & & $1=-1$ & $1.64(1.34-2.01)$ & & - & 0.0759 \\
\hline Female & $\geq 40$ & Economics & 13.36 & & $\longmapsto$ & $5.67(5.02-6.41)$ & & - & 0.0823 \\
\hline Female & $\geq 40$ & Health & 10.70 & & $\longmapsto$ & $4.40(3.86-5.02)$ & & - & 0.0815 \\
\hline Female & $\geq 40$ & Politics & 10.82 & & $\longmapsto$ & $4.46(3.90-5.10)$ & & & -0.0029 \\
\hline Female & $\geq 40$ & Education & 12.54 & & $\longmapsto$ & $5.27(4.54-6.12)$ & & - & 0.1001 \\
\hline Female & $\geq 40$ & Entertainment & 4.80 & & $\mapsto-1$ & $1.85(1.49-2.30)$ & & - & 0.1876 \\
\hline
\end{tabular}

Like in the bivariate analysis, there were some consistent results in the trivariate analysis. For example, the COVID-19 attention ratios increased with age, both for males and females in each topic of concern. Meanwhile, many detailed population differences were also clearly shown in these trivariate results. First, we can see that all of the groups presented different amounts of attention on the five topics of concern. In particular, females 40 years or older paid the greatest amount of attention to economic topics (OR 5.67, 95\% CI 5.02-6.41), followed by education topics (OR 5.27, 95\% CI 4.54-6.12). As a comparison, males in the same age group (ie, $\geq 40$ years) had the highest concerns regarding political topics (OR 4.83, 95\% CI 4.33-5.39), followed by economic (OR 4.53, 95\% CI 4.08-5.03) and education (OR 4.16, 95\% CI 3.71-4.68) topics. Second, the sentiment polarities of political topics were the lowest in all population groups, of which six had negative values. Lastly, the sentiment polarities of entertainment topics were always the highest among the five topics of concern across all population groups.

\section{COVID-19 Emotion Analysis}

We applied three different emotion models_Ekman's six basic emotions, Plutchik's eight primary emotions, and POMS six mood states - to perform emotion detection, both on the original 
tweets and the COVID-19 tweets. The comparison results are shown in Figures 7 and 8 . Figure 7 presents the mean intensity scores of the three emotion models, and Figure 8 shows the population distribution for each emotion from the models based on both original and COVID-19 tweets. As Ekman's six basic emotions (ie, anger, disgust, fear, joy, sadness, and surprise) are included in Plutchik's eight emotions, and these six common emotions had the same proportion rank in our experimental results, we only then analyzed Plutchik's and POMS emotions.

Figure 7. The mean intensity scores for the three emotion models. Scores range from 0 to 1 for each emotion. POMS: Profile of Mood States.

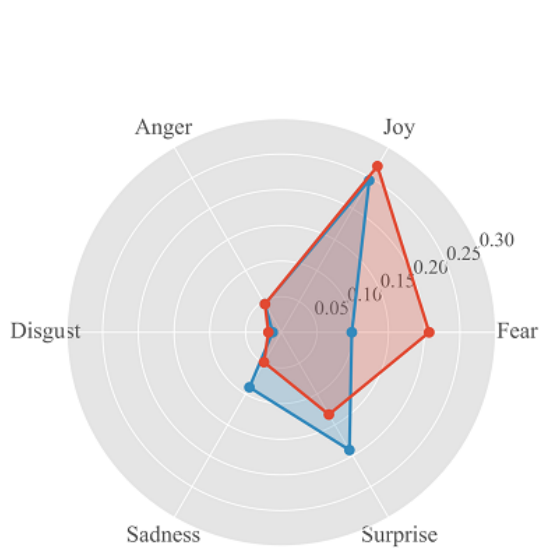

(a) Ekman Emotion Model

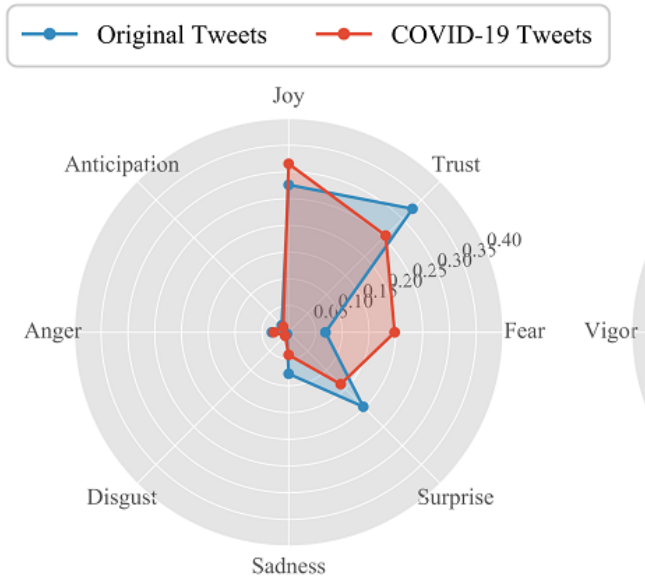

(b) Plutchik Emotion Model

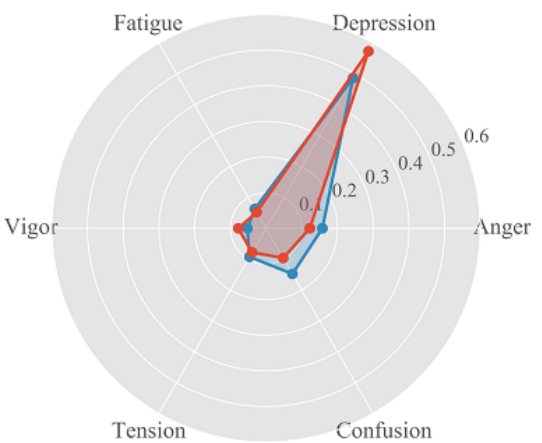

(c) POMS Emotion Model

Figure 8. The population distributions of the three emotion models. POMS: Profile of Mood States.

Original Tweets

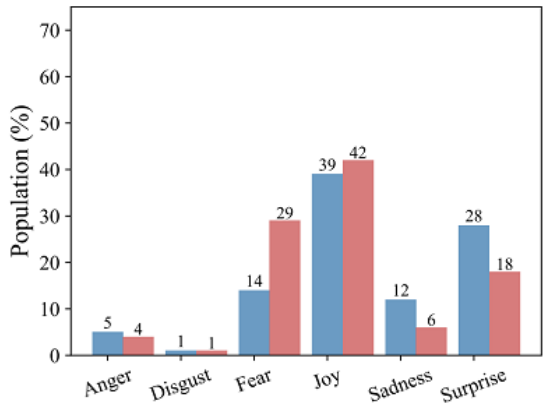

(a) Ekman Emotion Model

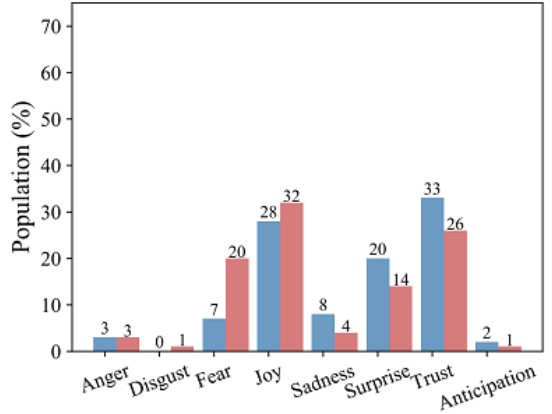

(b) Plutchik Emotion Model

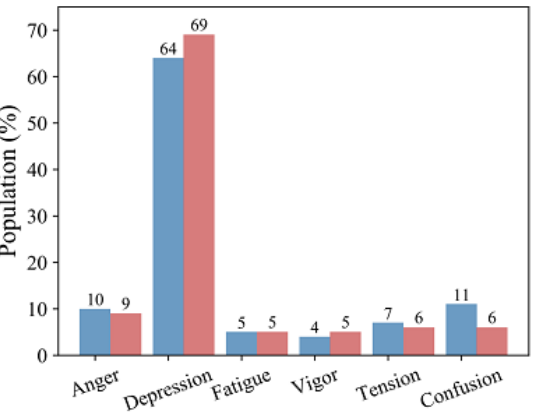

(c) POMS Emotion Model
In general, when Plutchik's emotion model was applied to the original tweets, trust, joy, and surprise were the highest emotions. When the model was applied to COVID-19 tweets, fear increased significantly, then joy, trust, and fear became the highest emotions. Meanwhile, when the POMS emotion model was applied to original tweets, depression was the most prominent emotion, and when applied to COVID-19 tweets, depression became even more prominent.

Afterward, we studied the differences in emotions considering the population characteristic attributes under COVID-19 by performing a chi-square test on each population attribute for each emotion. The results are shown in Multimedia Appendix 2. Figures 9 and 10 illustrate the emotion analysis by applying
Plutchik's and POMS models to each population characteristic. We observed differences in emotions with respect to population variables, but among all the dominant emotions after applying Plutchik's and POMS models, fear and depression had significantly different scores and proportions in different populations. A further detailed statistical analysis was conducted on these two emotions (see Figure 11). We can see that organizations expressed more fear and depression than individuals, and females expressed less fear and depression than males. With increasing age, fear and depression increased significantly; in addition, people expressed more fear regarding political and health topics, and more depression regarding entertainment, economic, and political topics. 
Figure 9. Plutchik emotion analysis on four population characteristics. Scores range from 0 to 1 for each emotion.

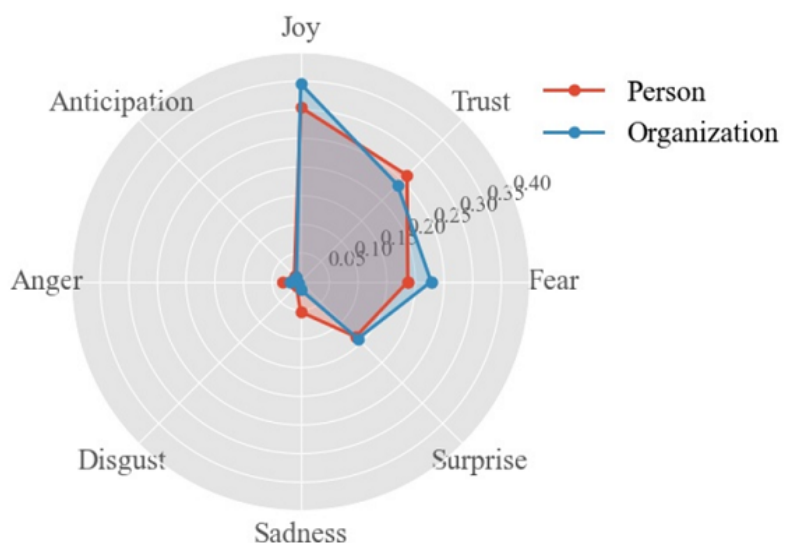

(a) User Type

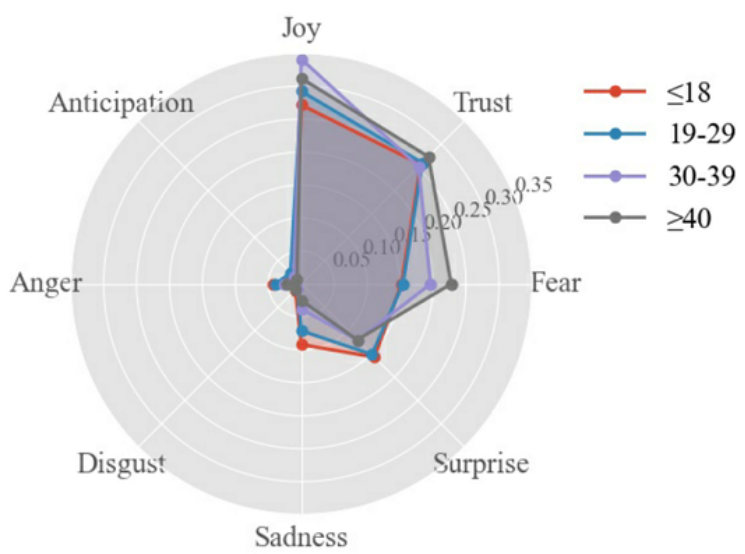

(c) Age

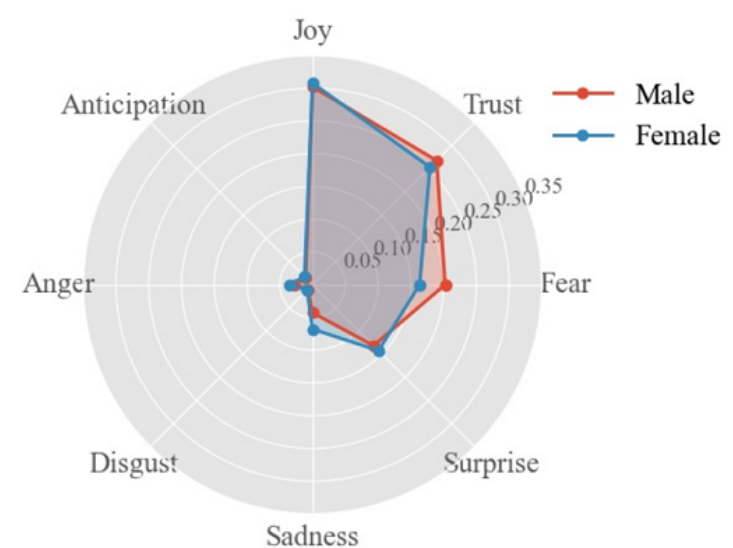

(b) Gender

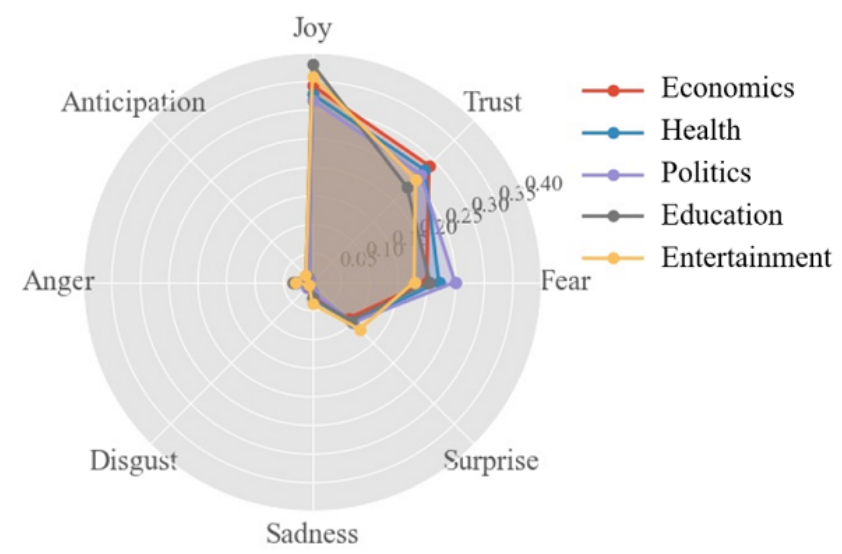

(d) Concern

Figure 10. Profile of Mood States (POMS) emotion analysis on four population characteristics. Scores range from 0 to 1 for each emotion.

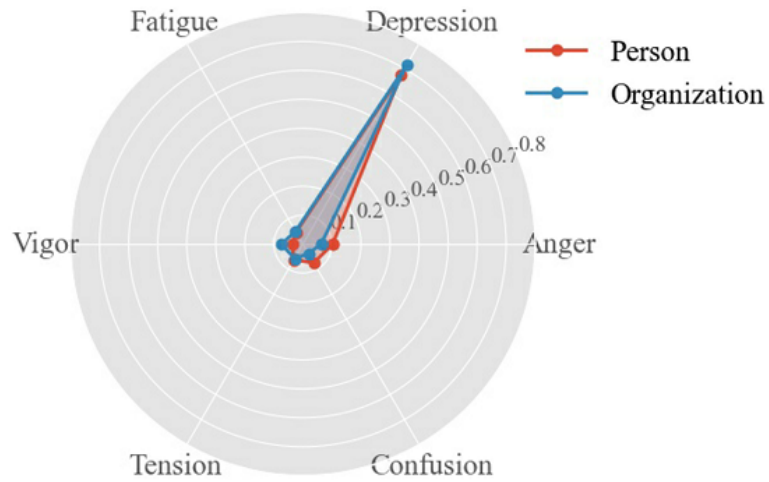

(a) User Type

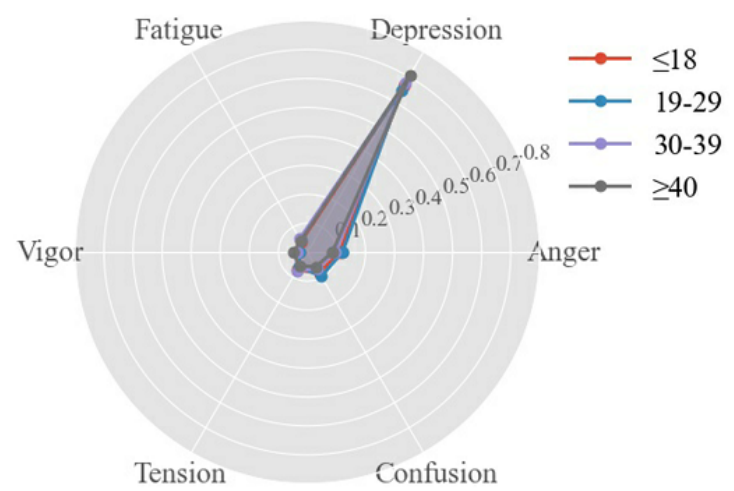

(c) Age

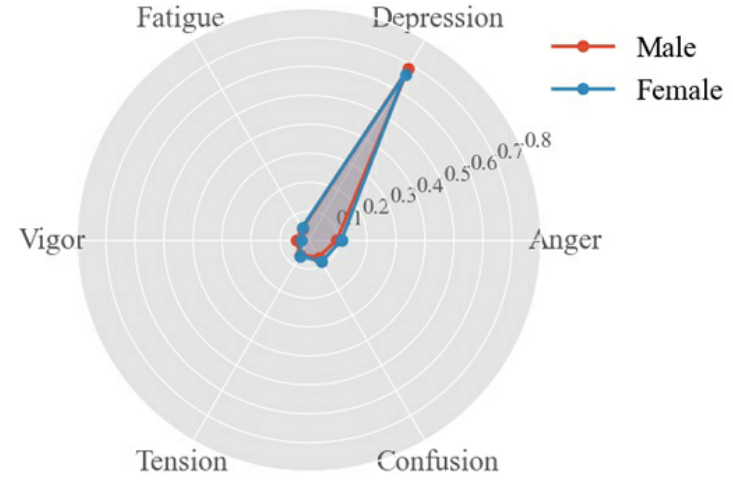

(b) Gender

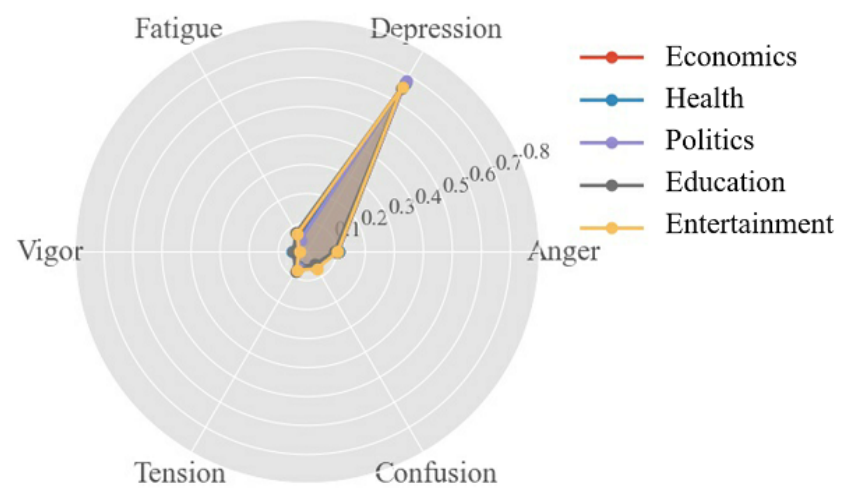

(d) Concern 
Figure 11. Statistical analysis of emotions related to COVID-19. OR: odds ratio.

\begin{tabular}{|c|c|c|c|c|c|c|c|c|}
\hline \multirow{2}{*}{$\begin{array}{l}\text { Variables } \\
\text { User type }\end{array}$} & \multicolumn{4}{|c|}{ Fear } & \multicolumn{4}{|c|}{ Depression } \\
\hline & Ratio (\%) & \multicolumn{2}{|c|}{ Forest Plot } & OR (95\% CI) & Ratio (\%) & \multicolumn{2}{|c|}{ Forest Plot } & OR $(95 \% \mathrm{CI})$ \\
\hline Person & 19.78 & & 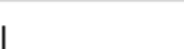 & 1 (ref) & 68.93 & & & 1 (ref) \\
\hline Organization & 23.16 & & $H$ & $1.22(1.15-1.30)$ & 72.93 & & $=1$ & $1.21(1.15-1.28)$ \\
\hline \multicolumn{9}{|l|}{ Gender } \\
\hline Male & 21.26 & & & 1 (ref) & 69.87 & & & 1 (ref) \\
\hline Female & 16.86 & $\uplus$ & & $0.75(0.69-0.81)$ & 67.06 & $=-1$ & & $0.88(0.82-0.94)$ \\
\hline \multicolumn{9}{|l|}{ Age (years) } \\
\hline$\leq 18$ & 14.88 & & & 1 (ref) & 65.47 & & & 1 (ref) \\
\hline $19-29$ & 17.78 & & $\mapsto-1$ & $1.24(1.10-1.39)$ & 66.51 & & -1 & $1.05(0.96-1.15)$ \\
\hline $30-39$ & 21.58 & & $\longmapsto$ & $1.57(1.39-1.79)$ & 67.91 & & -1 & $1.12(1.01-1.24)$ \\
\hline$\geq 40$ & 23.08 & & $\longmapsto$ & $1.72(1.53-1.92)$ & 73.36 & & $\mapsto-1$ & $1.45(1.33-1.59)$ \\
\hline \multicolumn{9}{|l|}{ Concern } \\
\hline Economics & 20.95 & & & 1 (ref) & 68.33 & & & 1 (ref) \\
\hline Health & 22.95 & & $1-1$ & $1.12(1.04-1.22)$ & 66.80 & - & & $0.93(0.87-1.00)$ \\
\hline Politics & 24.22 & & $\mapsto-1$ & $1.21(1.11-1.31)$ & 68.33 & 1 & 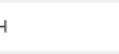 & $1.00(0.93-1.07)$ \\
\hline Education & 21.38 & & -1 & $1.03(0.94-1.12)$ & 65.33 & $=1$ & & $0.87(0.81-0.94)$ \\
\hline Entertainment & 21.43 & & -1 & $1.03(0.91-1.17)$ & 68.97 & & -1 & $1.03(0.92-1.15)$ \\
\hline
\end{tabular}

In summary regarding the emotion analysis, it can be concluded that the emotions differed between original tweets and COVID-19 tweets, and they further differed among different population groups during the COVID-19 pandemic.

\section{Discussion}

\section{Principal Findings}

In this study, we analyzed a large amount of Twitter data collected from August 7 to 12, 2020, during the COVID-19 pandemic. In the overall analysis, the average sentiment polarity of COVID-19-related tweets posted by participants was less positive than that of the original tweets. In addition, the population groups under each variable (ie, user type, gender, age, and concern) all showed significant differences $(P<.001)$ in response to COVID-19. In univariate analysis, organizations, as compared to individuals; males, as compared to females; and older people, as compared to young people were more concerned about the pandemic and had greater proportions of fear and depression emotions. In addition, the COVID-19 attention ratios of politics, education, and economics were relatively high, followed by health and entertainment, while the sentiment polarity of politics was the lowest, followed by economics, health, education, and entertainment.

Furthermore, the multivariate analyses showed more fine-grained and meaningful results. Among the findings, it is worth noting that not all female groups paid less attention to COVID-19 than male groups in the same age range, and not all groups' top concerns were the same. As age increased to above 30 years, females were gradually more concerned about COVID-19 than males. Moreover, females above 40 years of age were the group most concerned about COVID-19, and they were most concerned about economics and education. As a comparison, males in the same age group were most concerned about politics and economics. Males above 40 years of age and below 18 years of age were the least positive in sentiment. Among all the five topics of concern, the sentiment polarities of politics were the lowest in all population groups. These findings demonstrate that there exist population-level disparities in concerns and sentiments about COVID-19 in response to the pandemic during our research period.

We speculate that there are two reasons for the population-level differences. First, they are related to the concrete needs of specific age groups. For example, people older than 30 years of age may pay more attention to COVID-19 impacts on economics, while young people may concentrate more on education. Second, they are also related to the features of this novel coronavirus. Epidemiological studies have shown that the older population is more susceptible to COVID-19 and mortalities among this age group are higher than in other populations [13].

\section{Limitations}

The algorithm of demographic characteristic extraction used in this study is only capable of extracting three basic attributes: user type, gender, and age. Therefore, it is difficult for us to conduct a more detailed multivariable analysis compared with traditional questionnaire methods. In addition, the age range divisions were not fine-grained enough for COVID-19, especially for the group that was 40 years old or above, which covers a wide age range. To support the extraction of more attributes with finer granularity, we plan to optimize the current algorithm or seek new suitable and efficient algorithms for future studies. 


\section{Conclusions}

Through large-scale Twitter data mining, this study revealed that salient disparities exist among population groups in terms of their concerns and sentiments regarding COVID-19-related issues. Therefore, it is suggested that government agencies and social organizations should devote specialized attention and support to each population group based on their varied concerns and sentiments experienced during the pandemic. The open source code developed in this study, which was publicly released via GitHub [22], can be easily employed to explore the evolution of population groups regarding their wants, needs, and thoughts during the pandemic for future follow-ups. It can also be repurposed for research and interventions used in combatting other public health emergencies, thanks to the efficient and economic nature of its operation.

\section{Acknowledgments}

This research is supported by the National Natural Science Foundation of China (Grant Nos. 61876150 and 12026609) and the Science and Technology Program of the City of Xi' an (Grant Nos. 20YXYJ0009-12 and XA2020-RKXYJ-0105).

\section{Conflicts of Interest}

None declared.

\section{Multimedia Appendix 1}

Supplemental information about the M3 (multimodal, multilingual, and multi-attribute) model.

[DOCX File, 32 KB-Multimedia Appendix 1]

\section{Multimedia Appendix 2}

Extended details on the data analyses.

[DOCX File, $31 \mathrm{~KB}$-Multimedia Appendix 2]

\section{References}

1. Zhu N, Zhang D, Wang W, Li X, Yang B, Song J, China Novel Coronavirus Investigating and Research Team. A novel coronavirus from patients with pneumonia in China, 2019. N Engl J Med 2020 Feb 20;382(8):727-733 [FREE Full text] [doi: 10.1056/NEJMoa2001017] [Medline: 31978945]

2. WHO coronavirus disease (COVID-19) dashboard. World Health Organization. URL: https://covid19. who.int/ [accessed 2020-08-12]

3. Moreland A, Herlihy C, Tynan MA, Sunshine G, McCord RF, Hilton C, CDC Public Health Law Program, CDC COVID-19 Response Team, Mitigation Policy Analysis Unit. Timing of state and territorial COVID-19 stay-at-home orders and changes in population movement - United States, March 1-May 31, 2020. MMWR Morb Mortal Wkly Rep 2020 Sep 04;69(35):1198-1203 [FREE Full text] [doi: 10.15585/mmwr.mm6935a2] [Medline: 32881851]

4. Mayo Clinic Staff. COVID-19 quarantine, self-isolation and social distancing. Mayo Clinic. 2020. URL: https://www. mayoclinic.org/diseases-conditions/coronavirus/in-depth/coronavirus-quarantine-and-isolation/art-20484503 [accessed 2020-08-12]

5. Impact of COVID-19 on people's livelihoods, their health and our food systems. World Health Organization. 2020 Oct 13. URL: https://www.who.int/news/item/ 13-10-2020-impact-of-covid-19-on-people's-livelihoods-their-health-and-our-food-systems [accessed 2020-12-01]

6. Policy Brief: Education During COVID-19 and Beyond. New York, NY: United Nations; 2020 Aug. URL: https://www. un.org/development/desa/dspd/wp-content/uploads/sites/22/2020/08/sg policy brief covid-19 and education august 2020. pdf [accessed 2020-12-01]

7. United Nations Conference on Trade and Development. COVID-19 and E-Commerce: Impact on Businesses and Policy Responses. Geneva, Switzerland: United Nations; 2020 Nov 17. URL: https://unctad.org/system/files/official-document/ dtlstict2020d12 en.pdf [accessed 2021-02-26]

8. United Nations Conference on Trade and Development. Impact of the Pandemic on Trade and Development: Transitioning to a New Normal. Geneva, Switzerland: United Nations; 2020. URL: https://unctad.org/system/files/official-document/ osg2020d1 en.pdf [accessed 2021-02-26]

9. Lwin MO, Lu J, Sheldenkar A, Schulz PJ, Shin W, Gupta R, et al. Global sentiments surrounding the COVID-19 pandemic on Twitter: Analysis of twitter trends. JMIR Public Health Surveill 2020 May 22;6(2):e19447 [FREE Full text] [doi: 10.2196/19447] [Medline: 32412418 ]

10. Abd-Alrazaq A, Alhuwail D, Househ M, Hamdi M, Shah Z. Top concerns of tweeters during the COVID-19 pandemic: Infoveillance study. J Med Internet Res 2020 Apr 21;22(4):e19016 [FREE Full text] [doi: 10.2196/19016] [Medline: 32287039] 
11. Hung M, Lauren E, Hon ES, Birmingham WC, Xu J, Su S, et al. Social network analysis of COVID-19 sentiments: Application of artificial intelligence. J Med Internet Res 2020 Aug 18;22(8):e22590 [FREE Full text] [doi: 10.2196/22590] [Medline: 32750001]

12. Zhou F, Yu T, Du R, Fan G, Liu Y, Liu Z, et al. Clinical course and risk factors for mortality of adult inpatients with COVID-19 in Wuhan, China: A retrospective cohort study. Lancet 2020 Mar 28;395(10229):1054-1062 [FREE Full text] [doi: 10.1016/S0140-6736(20)30566-3] [Medline: $\underline{\text { 32171076] }}$

13. Yuki K, Fujiogi M, Koutsogiannaki S. COVID-19 pathophysiology: A review. Clin Immunol 2020 Jun;215:108427 [FREE Full text] [doi: 10.1016/i.clim.2020.108427] [Medline: 32325252]

14. Huang C, Wang Y, Li X, Ren L, Zhao J, Hu Y, et al. Clinical features of patients infected with 2019 novel coronavirus in Wuhan, China. Lancet 2020 Feb 15;395(10223):497-506 [FREE Full text] [doi: 10.1016/S0140-6736(20)30183-5] [Medline: $\underline{31986264]}$

15. Liu N, Zhang F, Wei C, Jia Y, Shang Z, Sun L, et al. Prevalence and predictors of PTSS during COVID-19 outbreak in China hardest-hit areas: Gender differences matter. Psychiatry Res 2020 May;287:112921 [FREE Full text] [doi: 10.1016/j.psychres.2020.112921] [Medline: $\underline{32240896]}$

16. Lu W, Wang H, Lin Y, Li L. Psychological status of medical workforce during the COVID-19 pandemic: A cross-sectional study. Psychiatry Res 2020 Jun;288:112936 [FREE Full text] [doi: 10.1016/j.psychres.2020.112936] [Medline: 32276196]

17. Nelson LM, Simard JF, Oluyomi A, Nava V, Rosas LG, Bondy M, et al. US public concerns about the COVID-19 pandemic from results of a survey given via social media. JAMA Intern Med 2020 Jul 01;180(7):1020-1022 [FREE Full text] [doi: 10.1001/jamainternmed.2020.1369] [Medline: 32259192]

18. Groarke JM, Berry E, Graham-Wisener L, McKenna-Plumley PE, McGlinchey E, Armour C. Loneliness in the UK during the COVID-19 pandemic: Cross-sectional results from the COVID-19 Psychological Wellbeing Study. PLoS One 2020;15(9):e0239698 [FREE Full text] [doi: 10.1371/journal.pone.0239698] [Medline: 32970764]

19. Azlan AA, Hamzah MR, Sern TJ, Ayub SH, Mohamad E. Public knowledge, attitudes and practices towards COVID-19: A cross-sectional study in Malaysia. PLoS One 2020;15(5):e0233668 [FREE Full text] [doi: 10.1371/journal.pone.0233668] [Medline: 32437434]

20. Ahmad AR, Murad HR. The impact of social media on panic during the COVID-19 pandemic in Iraqi Kurdistan: Online questionnaire study. J Med Internet Res 2020 May 19;22(5):e19556 [FREE Full text] [doi: 10.2196/19556] [Medline: 32369026]

21. van de Mortel TF. Faking it: Social desirability response bias in self-report research. Aust J Adv Nurs 2008;25(4):40-48 [FREE Full text]

22. Understanding concerns, sentiments and disparities of population groups during the COVID-19 pandemic. GitHub. 2020. URL: https://github.com/cyzhang87/EmulatedQuestionnaireOnTwitter [accessed 2021-02-26]

23. Sampled stream v1. Twitter Developer. 2020. URL: https://developer.twitter.com/en/docs/labs/sampled-stream/overview [accessed 2020-02-01]

24. Sampled stream. Twitter Developer. 2020. URL: https://developer.twitter.com/en/docs/twitter-api/tweets/sampled-stream/ introduction [accessed 2020-10-01]

25. COVID-19 stream. Twitter Developer. 2020. URL: https://developer.twitter.com/en/docs/labs/covid19-stream/filtering-rules [accessed 2020-07-01]

26. Wang Z, Hale S, Adelani DI, Grabowicz P, Hartman T, Flöck F, et al. Demographic inference and representative population estimates from multilingual social media data. In: Proceedings of the World Wide Web Conference (WWW '19). New York, NY: Association for Computing Machinery; 2019 May Presented at: The World Wide Web Conference (WWW '19); May 13-17, 2019; San Francisco, CA p. 2056-2067. [doi: 10.1145/3308558.3313684]

27. Rothe R, Timofte R, Van Gool L. Deep expectation of real and apparent age from a single image without facial landmarks. Int J Comput Vis 2016 Aug 10;126(2-4):144-157. [doi: 10.1007/s11263-016-0940-3]

28. Huang G, Liu Z, Van Der Maaten L, Weinberger KQ. Densely connected convolutional networks. In: Proceedings of the IEEE Conference on Computer Vision and Pattern Recognition (CVPR). New York, NY: IEEE; 2017 Presented at: IEEE Conference on Computer Vision and Pattern Recognition (CVPR); July 21-26, 2017; Honolulu, HI p. 2261-2269. [doi: 10.1109/cvpr.2017.243]

29. Hashimzade N, Myles G, Black J. A Dictionary of Economics. 5th edition. Oxford, UK: Oxford University Press; 2017.

30. Economics A-Z terms beginning with A. The Economist. 2020. URL: https://www.economist.com/economics-a-to-Z [accessed 2020-06-01]

31. Brown GW, McLean I, McMillan A. A Concise Oxford Dictionary of Politics and International Relations. 4th edition. Oxford, UK: Oxford University Press; 2018.

32. Hutto CJ, Gilbert E. VADER: A parsimonious rule-based model for sentiment analysis of social media text. In: Proceedings of the 8th International Conference on Weblogs and Social Media (ICWSM-14). 2014 Presented at: 8th International Conference on Weblogs and Social Media (ICWSM-14); June 1-4, 2014; Ann Arbor, MI p. 1-10 URL: http://comp. social.gatech.edu/papers/icwsm14.vader.hutto.pdf

33. Colneric N, Demsar J. Emotion recognition on Twitter: Comparative study and training a unison model. IEEE Trans Affect Comput 2020 Jul 1;11(3):433-446. [doi: 10.1109/taffc.2018.2807817] 
34. Ekman P. An argument for basic emotions. Cogn Emot 1992;6(3-4):169-200. [doi: 10.1080/02699939208411068]

35. Plutchik R. A general psychoevolutionary theory of emotion. In: Plutchik R, Kellerman H, editors. Emotion: Theory, Research, and Experience, Volume 1: Theories of Emotion. New York, NY: Academic Press; 1980:3-33.

36. McNair DM, Lorr M, Droppleman LF. Manual for the Profile of Mood States. San Diego, CA: Educational and Industrial Testing Services; 1971.

\section{Abbreviations}

DenseNet: dense convolutional network

M3: multimodal, multilingual, and multi-attribute

OR: odds ratio

POMS: Profile of Mood States

VADER: Valence Aware Dictionary and Emotional Reasoner

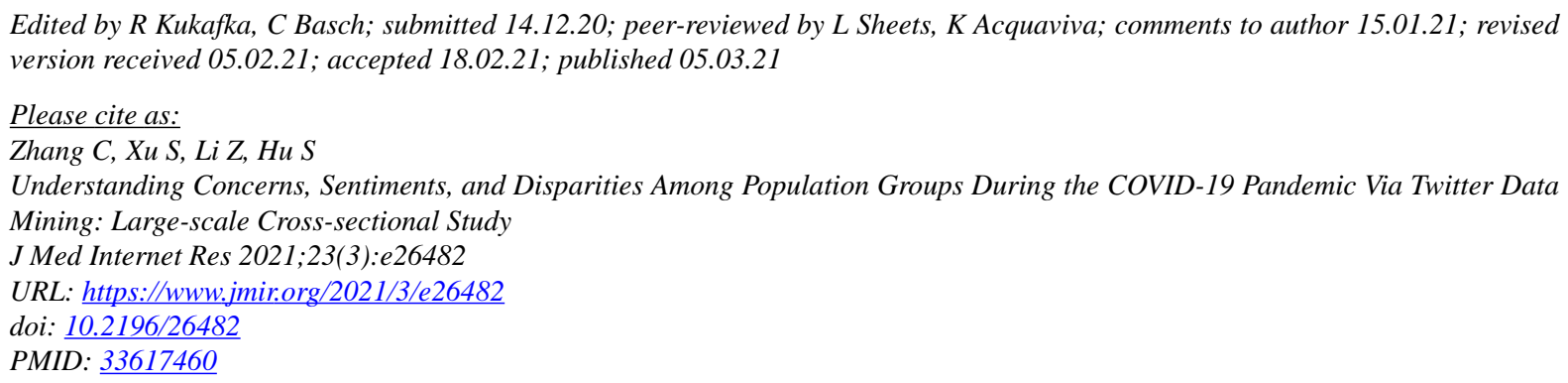

(C) Chunyan Zhang, Songhua Xu, Zongfang Li, Shunxu Hu. Originally published in the Journal of Medical Internet Research (http://www.jmir.org), 05.03.2021. This is an open-access article distributed under the terms of the Creative Commons Attribution License (https://creativecommons.org/licenses/by/4.0/), which permits unrestricted use, distribution, and reproduction in any medium, provided the original work, first published in the Journal of Medical Internet Research, is properly cited. The complete bibliographic information, a link to the original publication on http://www.jmir.org/, as well as this copyright and license information must be included. 